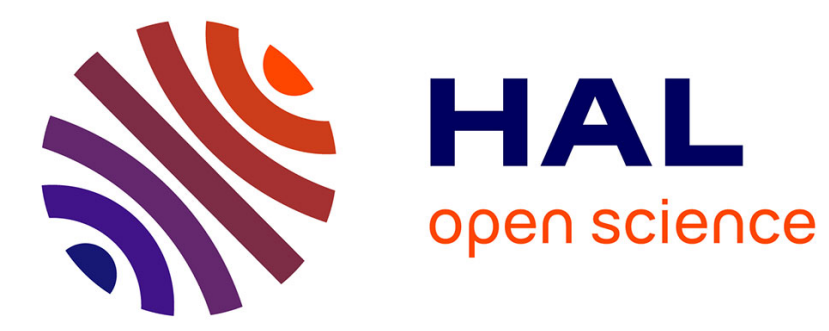

\title{
Water Vapor-Forced Greenhouse Warming over the Sahara Desert and the Recent Recovery from the Sahelian Drought
}

Amato T. Evan, Cyrille Flamant, Christophe Lavaysse, Cécile Kocha, Azzedine Saci

\section{To cite this version:}

Amato T. Evan, Cyrille Flamant, Christophe Lavaysse, Cécile Kocha, Azzedine Saci. Water VaporForced Greenhouse Warming over the Sahara Desert and the Recent Recovery from the Sahelian Drought. Journal of Climate, 2015, 28 (1), pp.108-123. 10.1175/JCLI-D-14-00039.1 . hal-01112972

\section{HAL Id: hal-01112972 \\ https://hal.science/hal-01112972}

Submitted on 21 Nov 2020

HAL is a multi-disciplinary open access archive for the deposit and dissemination of scientific research documents, whether they are published or not. The documents may come from teaching and research institutions in France or abroad, or from public or private research centers.
L'archive ouverte pluridisciplinaire HAL, est destinée au dépôt et à la diffusion de documents scientifiques de niveau recherche, publiés ou non, émanant des établissements d'enseignement et de recherche français ou étrangers, des laboratoires publics ou privés. 


\title{
Water Vapor-Forced Greenhouse Warming over the Sahara Desert and the Recent Recovery from the Sahelian Drought
}

\author{
AMATO T. Evan \\ Laboratoire Atmosphère, Milieux, Observations Spatiales, CNRS, and Université Pierre et Marie Curie, Paris, France, and \\ Scripps Institution of Oceanography, University of California, San Diego, La Jolla, California \\ CyRILLE FLAMANT \\ Laboratoire Atmosphère, Milieux, Observations Spatiales, CNRS, and Université Pierre et Marie Curie, Paris, France \\ CHRISTOPHE LAVAYSSE \\ National Center for Atmospheric Research, Boulder, Colorado \\ CÉCILE KOCHA \\ Laboratoire Atmosphère, Milieux, Observations Spatiales, CNRS, and Université Pierre et Marie Curie, Paris, France
}

\section{AZZEDINE SACI}

Office National de la Météorologie, Algiers, Dar El Bë̈da, Algeria

(Manuscript received 7 January 2014, in final form 19 September 2014)

\begin{abstract}
The Sahel region of West Africa experiences decadal swings between periods of drought and abundant rainfall, and a large body of work asserts that these variations in the West African monsoon are a response to changes in the temperatures of the tropical Atlantic and Indian Oceans. However, here it is shown that when forced by SST alone, most state-of-the-art climate models do not reproduce a statistically significant upward trend in Sahelian precipitation over the last 30 years and that those models with a significant upward trend in rainfall seem to achieve this result for disparate reasons. Here the role of the Saharan heat low (SHL) in the recovery from the Sahelian drought of the 1980s is examined. Using observations and reanalyses, it is demonstrated that there has been an upward trend in SHL temperature that is coincident with the drought recovery. A heat and moisture budget analysis of the SHL suggests that the rise in temperature is due to greenhouse warming by water vapor, but that changes in water vapor are strongly dependent upon the temperature of the SHL: a process termed the Saharan water vapor-temperature (SWAT) feedback. It is shown that the structure of the drought recovery is consistent with a warming SHL and is evidence of a fundamental, but not exclusive, role for the SHL in the recent increase in Sahelian monsoon rainfall.
\end{abstract}

\section{Introduction}

The Sahel region of West Africa is a semiarid grassland that lies in the transition zone from the Gulf of Guinea and the moist tropical climate to the south, to the hyper-arid (mean annual rainfall less than $100 \mathrm{~mm}$ )

Corresponding author address: Amato T. Evan, Scripps Institution of Oceanography, University of California, San Diego, 8622 Kennel Way, La Jolla, CA 92037.

E-mail: aevan@ucsd.edu
Sahara Desert to the north (Nicholson 1994). The Sahel receives the vast majority of its rainfall during the boreal summertime monsoon, and starting in the 1970s, the region experienced a severe drought that persisted through the 1980s. Conventional wisdom holds that such slowly evolving changes in Sahelian rainfall are the result of forcing by sea surface temperatures (SST). Observational and modeling studies suggest that Sahelian rainfall is anomalously positive when there exists an anomalous positive meridional SST gradient in the tropical Atlantic, La Niña-like conditions in the Pacific, 


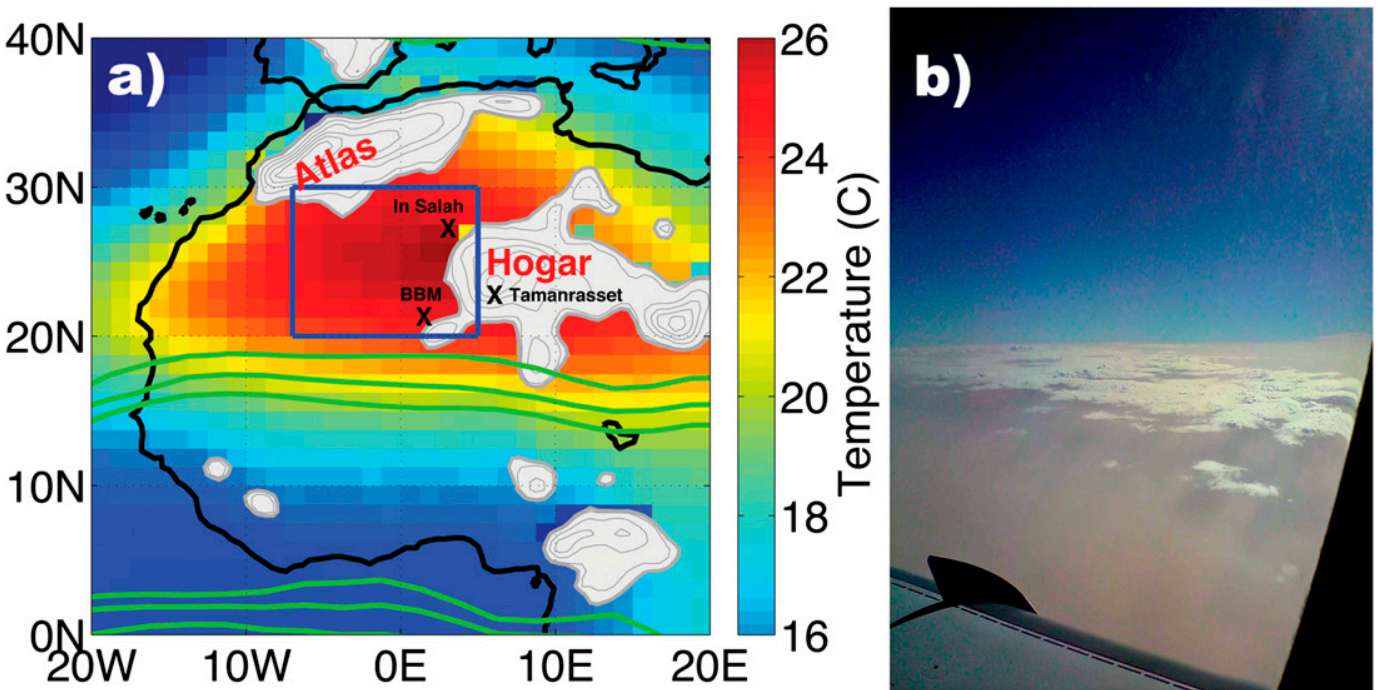

FIG. 1. Climate and geography of SHL region. (a) The long-term mean (1979-2011) 925-700-hPa summertime (June-August) temperatures over West Africa from MERRA reanalysis. Also shown are contours (green) of the long-term mean 1, 2, $3 \mathrm{~mm}_{\text {day }}{ }^{-1}$ isohyets. Regions mapped in white indicate average surface heights greater than $600 \mathrm{~m}$, with gray contours at 100-m height intervals for elevation greater than $600 \mathrm{~m}$ MSL. The Atlas and Hogar mountain ranges are indicated, as they form part of the physical border of the SHL region (blue box). Black crosses indicate areas where surface observations are available and are used here to validate the reanalysis (In Salah, Tamanrasset, and BBM). (b) An image from the Fennec field campaign taken over Mauritania on 17 Jun 2011, showing the transition into the SHL region, which is characterized by a deep and dusty boundary layer that is capped by shallow cumulus clouds, both of which result from low-level convergence into the SHL.

or anomalously cool waters in the equatorial Indian Ocean (Folland et al. 1986; Giannini et al. 2003; Held et al. 2005; Janicot et al. 1998, 2001; Martin and Thorncroft 2014; Vicente-Serrano et al. 2011). However, while the relationship between SST and Sahel rainfall seems to be robust when considering rainfall variations over the bulk of the twentieth century, does this relationship also explain the recent drought recovery?

In this paper, we examine the role of the Saharan heat low (SHL) in shaping year-to-year changes in Sahelian rainfall. The SHL is a region of summertime local maxima in surface- and boundary-layer temperatures and minima in surface pressure within the Sahara desert (Lavaysse et al. 2009) (Fig. 1a). The SHL is generally within $20^{\circ}-30^{\circ} \mathrm{N}, 7^{\circ} \mathrm{W}-5^{\circ} \mathrm{E}$ during the monsoon season, an area that is bounded by the Atlas Mountains to the north, the Hogar Mountains to the east, the Atlantic Ocean to the west, and the northern extent of the West African monsoon to the south (Fig. 1a). The dynamic adjustment to the high temperatures of the SHL is a lowlevel cyclonic circulation with ageostrophic convergence into the low's center, evidenced by observations of shallow clouds at the top of a deep and dusty boundary layer (Fig. 1b). Besides surface convergence, the SHL is associated with a pronounced midlevel anticyclonic circulation around an anomalously thick air column (Lavaysse et al. 2009; Rácz and Smith 1999), and at its southern boundary, the positive south-north temperature gradient is in thermal balance with the African easterly jet (Thorncroft and Blackburn 1999).

Previous work has established that the SHL influences the seasonality and intraseasonal variability of the West African monsoon (e.g., Chauvin et al. 2010; Lavaysse et al. 2009; Peyrillé and Lafore 2007; Thorncroft and Blackburn 1999). For example, Lavaysse et al. (2009) evidenced that the installation of the SHL into its climatological summertime position preludes the monsoon onset (Fig. 1a). Additionally, the SHL also undergoes synoptic-scale oscillations in intensity (Lavaysse et al. 2010; Chauvin et al. 2010), which can alter the intraseasonal variability of Sahelian precipitation; during a strong (warm) phase of the SHL, there is an intensification of the SHL's low-level cyclonic circulation, favoring increased precipitation in the central and eastern Sahel because of the anomalous surface southerlies, and drying in the western Sahel via the anomalous surface northerlies (Lavaysse et al. 2010).

The physical characteristics of the SHL and how they vary on synoptic-seasonal time scales have been corroborated by in situ and airborne observations made during the recent Fennec field campaign (Washington et al. 2012), and thus there is an emerging consensus regarding the role of the SHL in shaping the variability of the West African monsoon on intraseasonal and 
shorter time scales. However, far less is known about the importance of the SHL to year-to-year changes in the intensity of the monsoon. Although a negative correlation between surface pressure over the Sahara Desert and the intensity of the West African monsoon on interannual time scales has been noted in previous studies (Biasutti et al. 2009; Xue et al. 2010), these results were certainly influenced by the intraseasonal relationship between these two features described above. Martin and Thorncroft (2014) and Martin et al. (2014) noted that the SHL is intensified during seasons for which the Sahel was wetter than average and during a positive phase of the so-called Atlantic multidecadal oscillation, yet no clear mechanism for the warming and deepening of the SHL was provided.

In this paper, we describe how the thermodynamic and kinematic environment of the SHL has changed since 1979 and examine how these changes in the state of the SHL have affected Sahelian rainfall over the same time period. The remainder of our paper is organized as follows: In section 2, we describe the datasets and models used in this study. In section 3 , we evaluate the Sahel drought recovery in models from phase 5 of the Coupled Model Intercomparison Project (CMIP5), examine the results of an SHL heat and moisture budget analysis, and describe a positive feedback between temperature and moisture advection within the SHL. In section 4 , we discuss how changes in the temperature of the SHL may have at least partially fueled the recent Sahelian rainfall recovery. In section 5, a brief conclusions section is provided.

\section{Data and models}

Here we describe the observational data, precipitation climatologies, reanalysis products, climate model output, and radiative transfer model used in this study to improve understanding of the relationship between the SHL and the regional circulation and Sahelian rainfall. Websites for accessing these data are indicated in the acknowledgments.

\section{a. SHL observational data}

Observational data from meteorological stations within and near the SHL region are a key component of this study. All observational data used here are from within the country of Algeria (see all locations in Fig. 1a) and were provided directly by the Algerian Office National de la Météorologie (ONM), which also conducted quality control on all measurements. From ONM, we have 0000 and 1200 UTC sounding data from the station at Tamanrasset for the years 2001-10 and 1200 UTC sounding data from the station at In Salah for the years
2005-10, both for the months of July and August only. It is important to note that Tamanrasset is at an elevation of $1320 \mathrm{~m}$ above sea level. We use 3-hourly surface measurements of temperature from Tamanrasset (1980 2010), In Salah (1980-2010), and Bordj Badji Mokhtar (BBM; 1985-2010) for the months of June-August. ONM also provided measurements of downwelling shortwave and longwave radiation at Tamanrasset for the months of July and August over the years 2000-10.

\section{b. Precipitation climatologies}

Several precipitation climatologies are used here to quantify long-term changes in rainfall since 1979. The first is a Sahel rainfall index from the Joint Institute for the Study of the Atmosphere and Ocean (JISAO). The JISAO rainfall index is a June-October averaged time series of Sahelian rainfall based on "unadjusted" gridded rain gauge precipitation anomalies. The averaging region $10^{\circ}-20^{\circ} \mathrm{N}, 20^{\circ} \mathrm{W}-10^{\circ} \mathrm{E}$ is based on a rotated principal component analysis of African precipitation by Janowiak (1988).

We also use monthly-mean rainfall estimates from three climatologies that are merged records of precipitation estimates from satellite and rain gauges: the Global Precipitation Climatology Project (GPCP; Huffman et al. 2012), the National Oceanic and Atmospheric Administration (NOAA) National Centers for Environmental Prediction (NCEP) Climate Prediction Center (CPC) Merged Analysis of Precipitation (CMAP; Xie and Arkin 1997), and the Climate Research Unit (CRU) global land precipitation dataset (Harris et al. 2014).

\section{c. Reanalysis products}

In this paper, we make extensive use of reanalysis products from the Modern Era-Retrospective Analysis for Research and Applications (MERRA) dataset (Rienecker et al. 2011). In addition to analysis of the assimilated state products, we also use MERRA hourly and 3-hourly surface fluxes and temperature and moisture tendency products, which include assimilation tendencies. Where indicated in the text, we corroborate results from MERRA using data from the European Centre for Medium-Range Weather Forecasts Interim Re-Analysis (ERA-Interim; Dee et al. 2011), and the NCEP-U. S. Department of Energy (DOE) Atmospheric Model Intercomparison Project (AMIP)-II reanalysis (Kanamitsu et al. 2002).

\section{d. CMIP5 output}

We also examine output from models participating in CMIP5 (Taylor et al. 2012), specifically from the AMIP experiments. The AMIP experiments consist of atmospheric general circulation models that are forced by 
observed SSTs for the nominal period 1979-2008 and are intended to be comparable to observations. The models' respective centers, horizontal and vertical resolutions and references are available elsewhere (e.g., Roehrig et al. 2011) and are not reproduced here. However, model name expansions are provided in a searchable list at http:// www.ametsoc.org/PubsAcronymList, under the heading "Climatic, meteorological, oceanographic, and other" for the models discussed.

\section{e. Radiative transfer model}

Here we conduct surface radiative flux calculations using the Streamer radiative transfer model (Key and Schweiger 1998) in order to estimate the sensitivity of surface net radiative fluxes to changes in atmospheric water vapor. Streamer is a radiative transfer model that can be used for computing either intensities or fluxes for a wide variety of atmospheric and surface conditions. Here, fluxes are calculated for four streams using a discrete ordinate solver. The "midlatitude summer" profiles of temperature and moisture, which are based on data from Ellingson et al. (1991), were chosen from the Streamer standard profile set, since they compared well to temperature and moisture soundings from the SHL after linear scaling. Also included in the flux calculations were the standard desert background continental tropospheric aerosols, although changes in the amount of aerosols had little effect on the water vapor forcing sensitivity calculations.

To estimate the clear-sky surface forcing sensitivity to water vapor, we ran the model over one diurnal cycle for typical summertime desert ambient conditions (i.e., typical desert surface albedo and emissivity). For each run, we linearly scaled the specific humidity profile so that the vertically integrated water vapor ranged from zero to conditions more typical of a moist tropical environment. We calculated the diurnally averaged surface forcing for each moisture profile and estimated surface water vapor forcing by subtracting this value from the run with a completely dry atmosphere.

\section{Results}

To motivate our climatological analysis of the SHL and its influence on the West African monsoon, we first examine the representation of the recent Sahelian drought recovery in 27 state-of-the-art climate models. We then present a climatology of the SHL for the period of 19792012 and identify upward trends in the temperature of the SHL over this period in time. This is followed by a heat and moisture budget analysis of the SHL using observations and reanalysis data in order to elucidate the source of SHL temperature trends. This section ends with

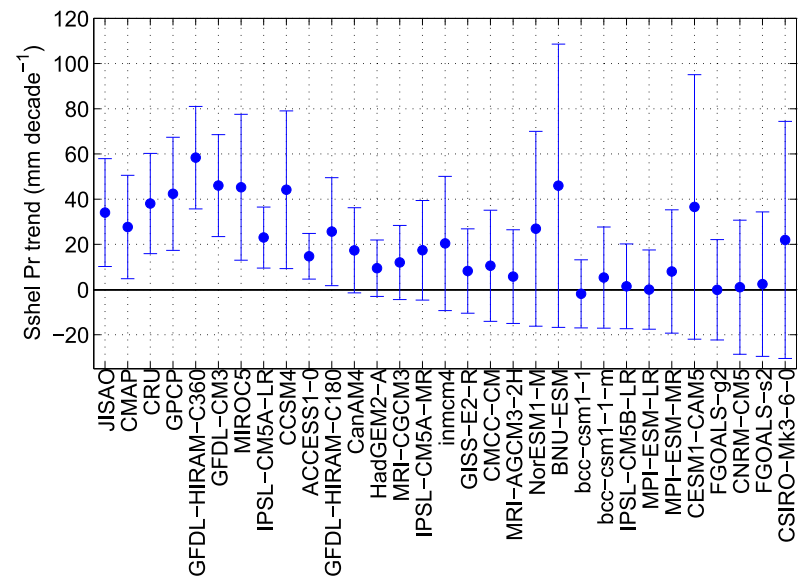

FIG. 2. Trends in Sahel precipitation from observations and models. Shown are the trends in June-September Sahelian accumulated precipitation from observations (first four from the left) and output from the AMIP runs of CMIP5 models (all others). The blue filled circles indicate mean trends from 1979 to 2008, and the error bars indicate the trends' 95\% confidence levels. The CESM1CAM5 only has AMIP data available through 2005. However, a plot for trends from 1983 to 2005 yields very similar results.

a description of a newly identified positive feedback between temperature and moisture within the SHL.

\section{a. Sahel rainfall recovery in CMIP5 models}

We calculated the linear trends in the seasonal (JuneSeptember) CMIP5-AMIP and observed (CMAP, CRU, GPCP, and JISAO) accumulated precipitation over the period 1983-2009 using the same averaging area of the JISAO index $\left(10^{\circ}-20^{\circ} \mathrm{N}, 10^{\circ} \mathrm{W}-20^{\circ} \mathrm{E}\right)$. All four observational datasets exhibit upward trends in Sahelian rainfall that are statistically different from zero at the 95\% confidence level (Fig. 2), and the multiobservational dataset mean trend in Sahelian rainfall is $35.5 \pm 23.5 \mathrm{~mm} \mathrm{decade}^{-1}$ (all confidence intervals presented in this paper are based on the $t$ score of a twotailed $t$ test). Consistent with the results of Roehrig et al. (2011), the majority of CMIP5 models show an upward trend in Sahelian precipitation over this period, with only 3 of the 27 CMIP5-AMIP models showing a downward trend in rainfall (Fig. 2). The multimodel mean trend in Sahelian rainfall is $18.7 \pm 26.8 \mathrm{~mm} \mathrm{decade}^{-1}$, which is approximately half of the observed value.

Only $26 \%$ (7) of the AMIP models exhibit precipitation trends that are statistically different from zero at the $95 \%$ confidence level, and one additional model has statistically significant upward trends at the $90 \%$ confidence level. We achieve similar results considering just the 16 CMIP5 models for which three ensemble members of the AMIP runs were available. Here, 6 of the 16 models (38\%) exhibited statistically significant upward trends in Sahelian rainfall ( $p$ value $<0.05$; not shown). 
Next, we show that the seven AMIP models with a statistically significant upward trend in rainfall (Fig. 2) appear to obtain this result for distinct reasons. We estimate the sensitivity of seasonally (June-September) accumulated Sahelian precipitation to seasonal mean surface temperature $\partial \operatorname{Pr} / \partial T\left(\mathrm{~mm} \mathrm{~K}^{-1}\right)$ by regressing the surface temperature fields onto the models' Sahel precipitation time series for the years 1979-2008. Figure 3 contains maps of $\partial \operatorname{Pr} / \partial T$ for the seven models having statistically significant upward trends in Sahelian precipitation, as well as for the CRU and GPCP observational datasets (we use the AMIP SST dataset for the observational estimates of $\partial \operatorname{Pr} / \partial T$ ).

Theory and observations suggest that subdecadal variability in Sahelian precipitation is negatively correlated with El Niño-Southern Oscillation (ENSO) (e.g., Giannini et al. 2003). This ENSO-Sahel rainfall relationship is clearly indicated in the maps of $\partial \mathrm{Pr} / \partial T$ for the GPCP and CRU rainfall data, with positive sensitivity values near the Maritime Continent $\left(120^{\circ}-150^{\circ} \mathrm{E}\right.$ and from $5^{\circ} \mathrm{S}$ through the extent of the tropics to the north) and negative values in the cold-tongue region (along the equator and $5^{\circ}$ latitude to the north and south). Previous work has also shown that Sahelian rainfall should be positively correlated with the tropical Atlantic meridional SST gradient (e.g., Folland et al. 1986). However, the sensitivity maps calculated from observations do not show the influence of the tropical Atlantic SST gradient; there is a lack of negative values in the equatorial Atlantic and tropical South Atlantic, and the positive values in the North Atlantic do not mimic the characteristic curve that follows the contour of the West African coastline (e.g., Cassou et al. 2004; Martin et al. 2014). As such, and only with respect to the recent drought recovery, the spatial structure of the regression coefficients for the CRU and GPCP datasets suggests that the drought recovery is not being directly forced by an anomalously positive SST gradient in the tropical Atlantic Ocean.

From the maps of $\partial \operatorname{Pr} / \partial T$ calculated with the model output, these seven CMIP5 models can be grouped into four categories: those with a positive sensitivity to tropical North Atlantic SSTs (HiRAM-C360 and GFDL CM3); those with a positive sensitivity to SSTs in the tropical North and South Atlantic (CCSM4 and MIROC5); those with a positive sensitivity to a La Niña-like state in the Pacific (MIROC5 and HiRAMC180); and those with a relatively weak sensitivity to SSTs in general (ACCESS1.0 and IPSL-CM5A-LR). None of the CMIP5 models clearly reproduces both of the salient features seen in the sensitivity maps calculated with the observed rainfall data. For example, the spatial structure of the Atlantic SST sensitivities in the
GFDL CM3 model is very similar to those in the CRU and GPCP maps, yet here there is no obvious ENSOlike signal in the Pacific. The MIROC5 and HIRAMC180 models exhibit sensitivities in the Pacific that are consistent with the observational maps, yet these models do not appear to be sensitive to temperatures in the tropical and extratropical North Atlantic. The three GFDL models, the MIROC5 model, and the regression maps based on observations show positive sensitivities of Sahel rainfall to surface temperatures in the Mediterranean Sea, possibly indicative of an increase in moisture flux from the Mediterranean Sea to the Sahel (Martin et al. 2014).

The $\partial \operatorname{Pr} / \partial T$ maps in Fig. 3 suggest that, although these seven CMIP5 models do exhibit a statistically significant upward trend in Sahelian rainfall, they appear to do so for different reasons. This lack of consistency between models and observations and between observations and published literature suggests that the causes of the recent recovery in Sahelian rainfall are not completely understood. These results are still consistent with the large body of research examining the relationship between SST variability and rainfall changes in the Sahel over the entire twentieth century, primarily because these SST sensitivities are nonstationary (Diatta and Fink 2014). For example, results from analysis of the relationship between SST and Sahelian rainfall over the entirety of the twentieth century (e.g., Folland et al. 1986; Held et al. 2005) may not be sufficient to understand the role SST variability has played in the increase in rainfall from the early 1980s through the first decade of the twenty-first century. We note that recent work has shown that Sahelian rainfall may be more sensitive to the so-called "relative SST," where the relative SST of any location is just the in situ SST minus the tropical mean SST (Giannini et al. 2013). However, we repeated the analysis in Fig. 3 using relative SST and found nearly identical results. We refer the reader to Biasutti (2013) and Roehrig et al. (2011) for a more exhaustive analysis of the representation of Sahelian rainfall in CMIP5 models.

\section{b. Trends in SHL temperature}

We propose that the recent recovery in Sahel rainfall may be partially forced by regional circulation changes associated with a simultaneous rise in the temperature of the SHL. We start by examining variability in the physical properties of the SHL from 1979-2012, for which reanalysis output and in situ observations are available. We firstly consider a seasonal mean (July-August) time series of surface temperature from MERRA averaged over the SHL region $\left(20^{\circ}-30^{\circ} \mathrm{N}, 7^{\circ} \mathrm{W}-5^{\circ} \mathrm{E}\right)$. Within the SHL reanalysis (hereafter the term reanalysis refers to MERRA, 

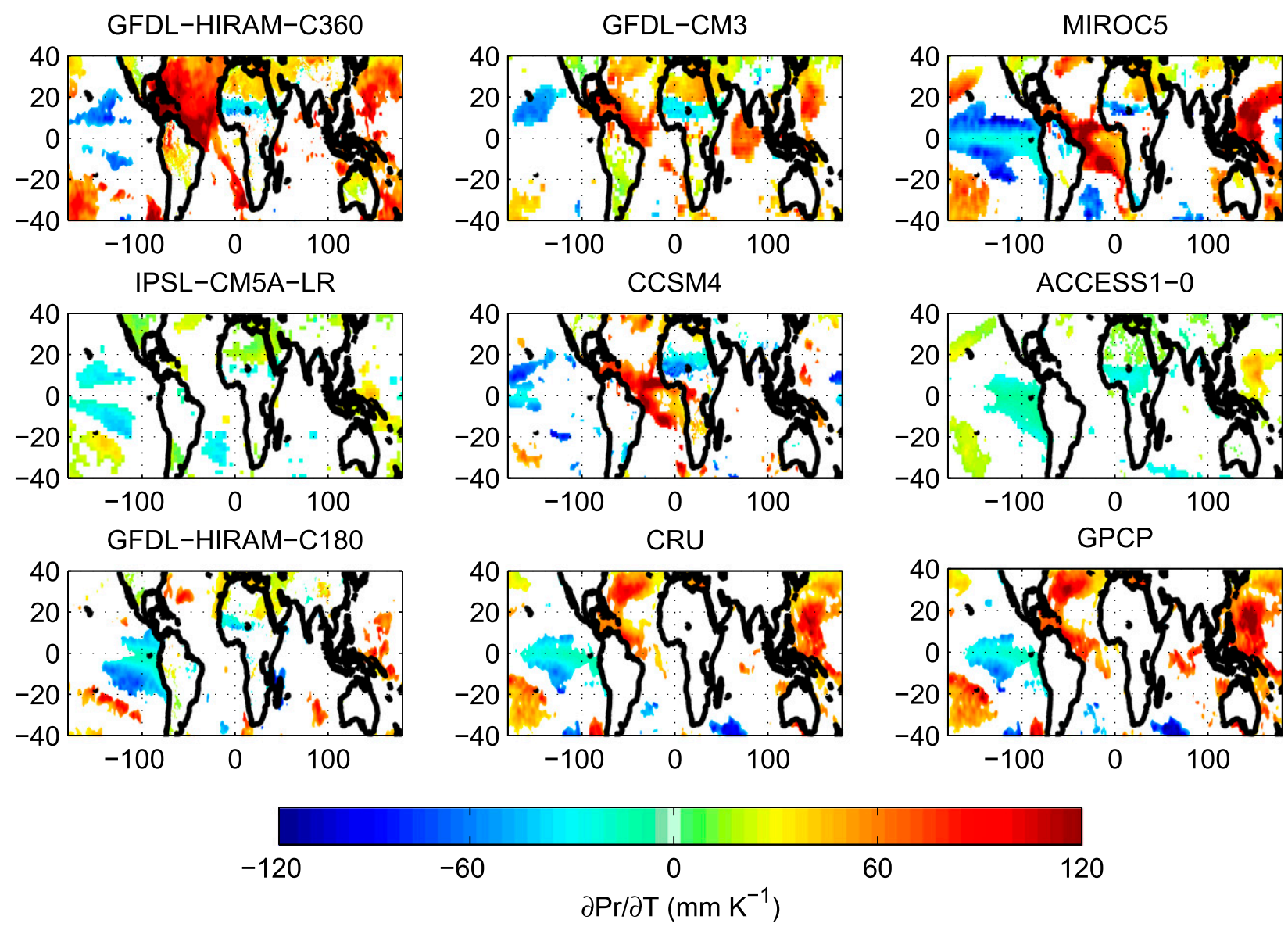

FIG. 3. Sensitivity of Sahelian precipitation to surface temperature in CMIP5 models and observations. Shown are coefficients ( $\partial \mathrm{Pr} / \partial T)$ of the regression of seasonal (June-September) Sahelian accumulated precipitation from CMIP5 models and observations onto observed seasonal mean surface temperature. Only regression coefficients significant at the $90 \%$ level are shown.

unless otherwise stated) summertime surface and 925700-hPa temperatures are very well correlated $(r>0.9$; $p$ value $<0.01$ ); thus, surface temperature anomalies are a good proxy for those of the boundary layer in this region (Lavaysse et al. 2009). We also examine time series of July-August averaged surface temperatures from three synoptic stations within (or just outside) the SHL region in Algeria: BBM, In Salah, and Tamanrasset (see locations in Fig. 1a). We again note that our observational analysis is limited to the months of July and August, since this is the time period during which we have qualitycontrolled observations.

There is excellent agreement between these seasonal (July-August) time series of SHL surface temperatures from reanalysis and observations (Fig. 4a). The correlation coefficients between temperatures from reanalysis and at Tamanrasset (0.72), In Salah (0.81), and BBM $(0.58)$ are all statistically significant with a $p$ value $<0.01$ ( $r$ values indicated parenthetically). Furthermore, the temperature time series exhibit statistically significant ( $p$ value $<0.01$ ) trends of $0.4^{\circ} \mathrm{C} \mathrm{decade}^{-1}$ from MERRA and Tamanrasset, and $0.6^{\circ} \mathrm{C}$ decade ${ }^{-1}$ at In Salah. The trend of $0.2^{\circ} \mathrm{Cdecade}^{-1}$ at $\mathrm{BBM}$ is not statistically significant, as available data begin in 1985 and thus are heavily influenced by the anomalously warm year of 1987 . This trend is $0.3^{\circ} \mathrm{Cdecade}^{-1}$ ( $p$ value $=0.03$ ) if we exclude 1987 from the trend calculation.

There are corroborating increases in SHL temperatures over the same time period in the NCEP-DOE and ECMWF reanalyses (not shown) and in satelliteretrieved lower-tropospheric temperatures from the Microwave Sounding Unit (Collins 2011). Although the observations and satellite retrievals are independent, the data from both may be assimilated into the reanalysis; thus, the reanalysis temperatures may not be independent of the observations. Furthermore, here we only consider a static definition of the location of the SHL, but the location of the SHL can vary on a variety of time scales. We repeated this analysis using the SHL tracking method described in Lavaysse et al. (2009), which gave identical results, and thus we use a static definition of the SHL's geographical extent for simplicity. 

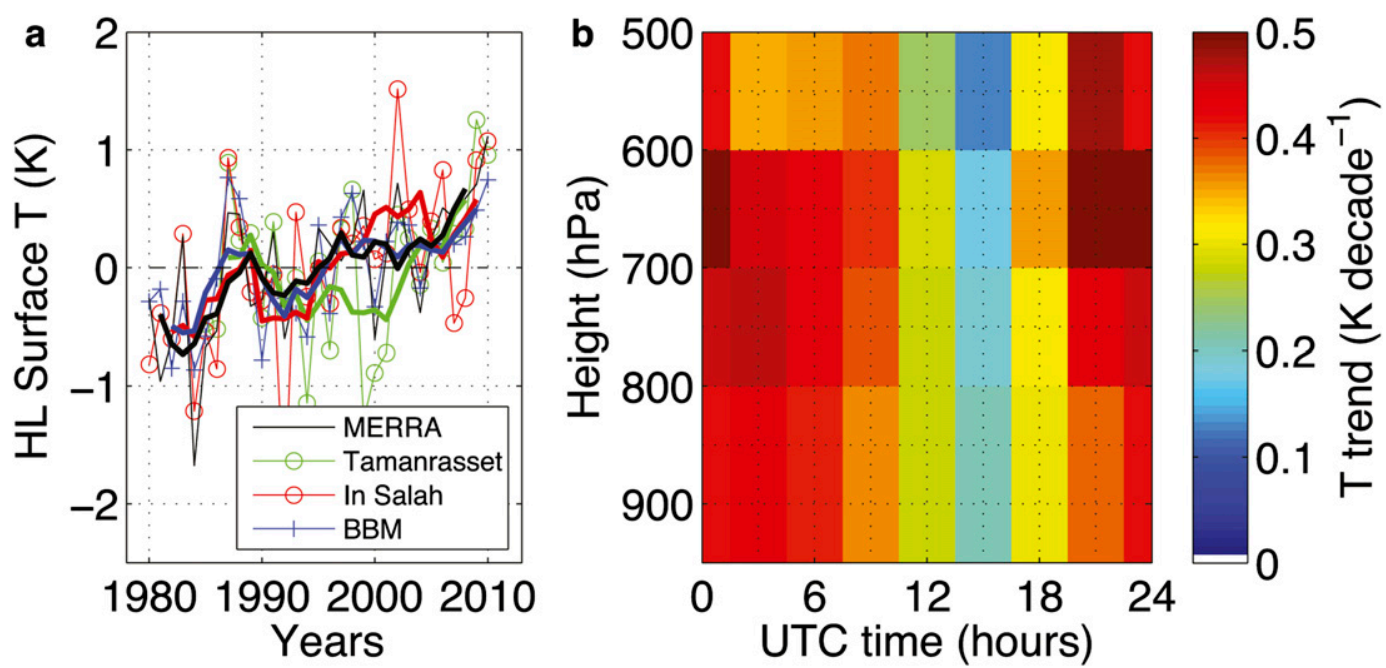

FIG. 4. Trends in SHL temperature. (a) Mean July-August surface temperatures averaged over the SHL region from reanalysis and observations at Tamanrasset, In Salah, and BBM (see locations in Fig. 1a), with the 5-yr low-pass filtered time series indicated by the thick lines. Smoothing is accomplished by applying recursive three-point running mean filters to the time series data. All time series are for the period 1980-2010, except for BBM, which begins in 1985. (b) The June-August SHL temperature trends from MERRA, as a function of hour (UTC) and height in pressure $(\mathrm{hPa})$. Here trends are calculated for the period 1979-2012.

A plot of MERRA SHL summertime (hereafter summertime refers to the months of June-August) temperature trends (1979-2012) as a function of height in pressure and time in UTC shows that the temperature trends are nearly homogeneous from the surface through $500 \mathrm{hPa}$ (Fig. 4b), likely as a result of the deep desert boundary layer (Lavaysse et al. 2009; Rácz and Smith 1999) (Fig. 1b). In addition, tropospheric temperatures are increasing the quickest during the nighttime hours; the near-surface trends in temperature are greater than $0.4^{\circ} \mathrm{Cdecade}^{-1}$ from $2100-0600 \mathrm{UTC}$, and are approximately $0.2^{\circ} \mathrm{C} \mathrm{decade}^{-1}$ at $1500 \mathrm{UTC}$ (Fig. 4b).

Although there are upward trends in surface temperature across the Sahara (Collins 2011), the increase in SHL temperature is unique with respect to regional temperature changes. To show this, we made a composite map of the difference in SHL atmospheric temperatures from reanalysis using the 10 warmest minus the 10 coolest summers. We defined the summer temperature of the SHL as the mean June-August air temperature averaged from the surface up to $700 \mathrm{hPa}$ and extending radially out from the SHL center $\left(25^{\circ} \mathrm{N}\right.$, $1^{\circ} \mathrm{W}$ ) by $550 \mathrm{~km}$ (blue box, Fig. 5). We plotted these temperature differences as a function of height in pressure, and radial distance from the SHL center. From the surface to $500 \mathrm{hPa}$, and out to a distance of $1000 \mathrm{~km}$ from the SHL center, the temperature difference is positive and everywhere positive. Therefore, for each vertical level, we calculated the temperature difference anomaly relative to the mean change at that height.
The resulting difference map (Fig. 5) shows that up to a height of $600 \mathrm{hPa}$, for summers in which the SHL is anomalously warm, the SHL is warming more than the surrounding environment (Fig. 5). At $925 \mathrm{hPa}$, the

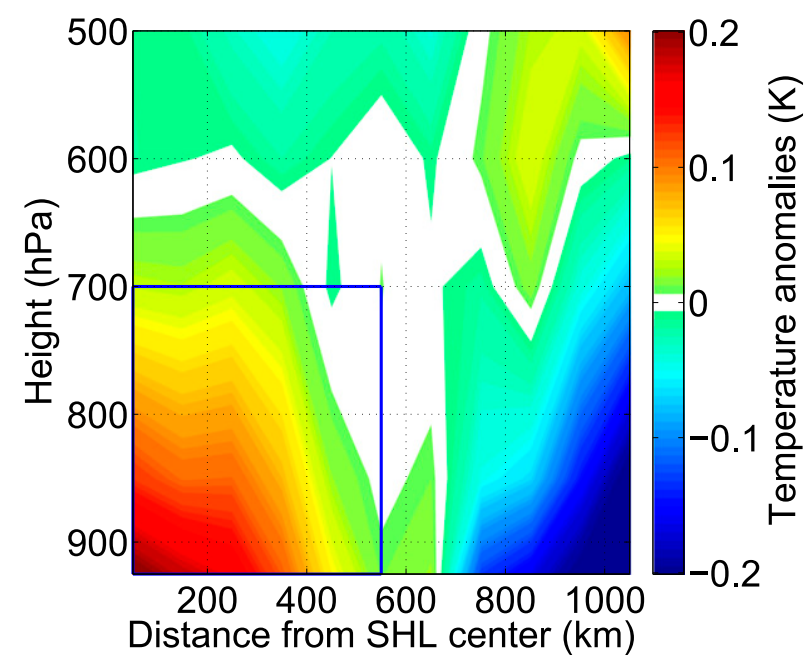

FIG. 5. Anomalous temperature differences for SHL warm and cool periods. Shown are differences in atmospheric temperature, composited around the 10 warmest minus the 10 coolest SHL seasons (Fig. 4a), as a function of height in pressure above the surface $(\mathrm{hPa})$ and radial distance from the SHL center $\left(25^{\circ} \mathrm{N}, 1^{\circ} \mathrm{W}\right)$. SHL temperature is defined as the average summertime temperature (June-August) of the surface-700-hPa layer, and extending radially from the SHL center to a distance of $550 \mathrm{~km}$ (blue box). All temperature differences were positive and statistically significant ( $p$ value $<0.05$ ), and temperature differences are plotted as the anomalies about the mean temperature difference at each height. 
anomalous temperature gradient, extending radially outward from the SHL center, is $0.5^{\circ} \mathrm{C}(1000 \mathrm{~km})^{-1}$. At $850 \mathrm{hPa}$, this difference is $0.3^{\circ} \mathrm{C}(1000 \mathrm{~km})^{-1}$; at $700 \mathrm{hPa}$, it is $0.1^{\circ} \mathrm{C}(1000 \mathrm{~km})^{-1}$; and it is effectively zero at and above $600 \mathrm{hPa}$. Thus, during summers in which the SHL is anomalously warm, we expect a deepening of the surface low relative to the surrounding environment, which suggests an associated strengthening of the SHL low-level convergence.

\section{c. Heat budget analysis}

The diurnal pattern in SHL temperature trends (Fig. 4b) is consistent with greenhouse warming, and we propose this greenhouse warming is due to changes in atmospheric water vapor. Thus, as the concentration of atmospheric moisture increases, the atmosphere absorbs more longwave (LW) radiation emitted by the surface, warming the atmosphere and the surface. Greenhouse warming is more pronounced during the nighttime hours because 1) this is when radiative heat losses are the greatest, and 2) shortwave (SW) scattering by water vapor nearly offsets the surface LW warming during the daytime hours.

In both observations and the reanalysis, year-to-year changes in the net LW surface flux are dominated by small changes in atmospheric water vapor. From MERRA, the summertime SHL nighttime net LW surface flux is highly correlated with water vapor path (WVP), which is the column-integrated specific humidity. The $r$ value of the correlation of WVP and the net LW surface flux is 0.89 ( $p$ value $<0.01$ ), and the slope of the regression of the net LW surface flux onto WVP is $0.75 \mathrm{~W} \mathrm{~m}^{-2}\left(\mathrm{~kg} \mathrm{~m}^{-2}\right)^{-1}$ (Fig. 6), which is statistically different from zero ( $p$ value $<0.01)$. We estimated the nighttime net July-August LW flux at Tamanrasset using measurements of downwelling LW radiation made at 0400 UTC, and a calculation of the upward LW surface flux using the synoptic station measurements of temperature at 0400 UTC (with the surface emissivity from MERRA). WVP at Tamanrasset is calculated from the 0000 UTC soundings. For the years 2001-10, the period for which all data were available, the JulyAugust mean nighttime WVP and net LW surface fluxes are correlated with an $r$ value of 0.94 ( $p$ value $<0.01$ ) The slope of the regression of WVP onto the LW fluxes is $3.6 \mathrm{~W} \mathrm{~m}^{-2}\left(\mathrm{~kg} \mathrm{~m}^{-2}\right)^{-1}$ (Fig. 6), which is statistically different from zero ( $p$ value $<0.01$ ).

It is not entirely surprising that the net surface radiative fluxes and SHL temperature tendencies over this desert region are highly sensitive to changes in water vapor; surface radiative forcing by atmospheric moisture is approximately proportional to the natural logarithm of total column water vapor. Thus, the fact that there is

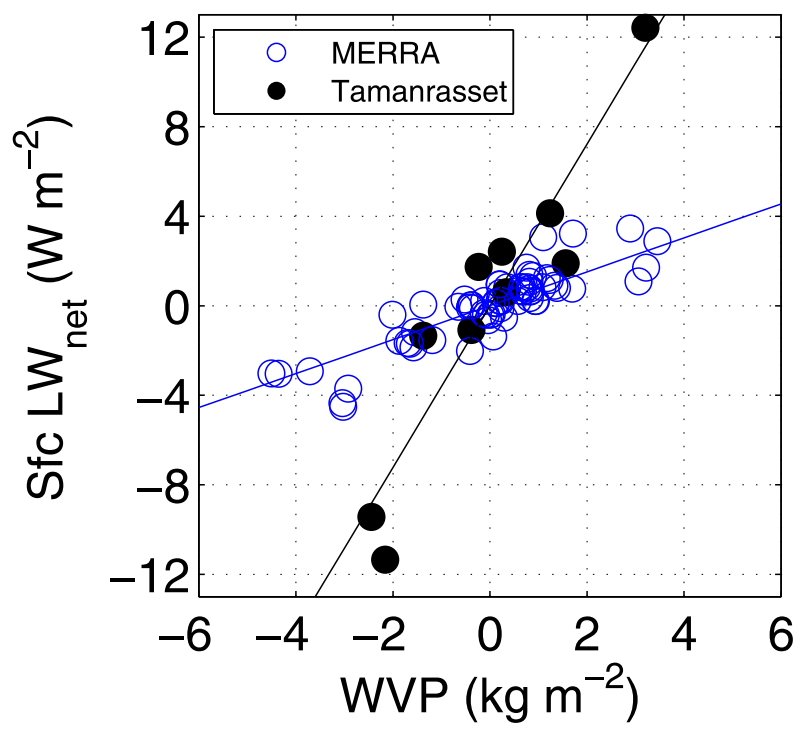

FIG. 6. Relationship between WVP and the net LW surface flux. Shown is a scatterplot of seasonal mean SHL WVP and the net surface LW flux from observations at Tamanrasset (black) and MERRA (blue). The observations of LW radiation correspond to 0400 UTC, while WVP is calculated from the 0000 UTC sounding. The MERRA data are averaged over 2300-0400 UTC. The MERRA seasonal means are calculated for the June-August time period and over 1979-2012, while the observations are July-August means from 2001 to 2010. The slopes of the best-fit lines are 0.75 (MERRA) and 3.6 (Tamanrasset) $\mathrm{W} \mathrm{m}^{-2}\left(\mathrm{~kg} \mathrm{~m}^{-2}\right)^{-1}$ and are statistically different from zero $(p$ value $<0.01)$.

so little moisture in the atmosphere means that small changes in water vapor can induce large radiative flux changes at the surface. For a background WVP of $15.7 \mathrm{~kg} \mathrm{~m}^{-2}$, which is the long-term mean 0000 UTC WVP from the Tamanrasset soundings, calculations with Streamer give a mean SHL forcing sensitivity (also at 0000 UTC) of $2.3 \mathrm{~W} \mathrm{~m}^{-2}\left(\mathrm{~kg} \mathrm{~m}^{-2}\right)^{-1}$, which is smaller than the sensitivity calculated from observations at Tamanrasset (Fig. 6). For a background WVP of $21.1 \mathrm{~kg} \mathrm{~m}^{-2}$, which is the mean MERRA WVP averaged over the SHL, the Streamer calculations give a forcing sensitivity of $1.8 \mathrm{~W} \mathrm{~m}^{-2}\left(\mathrm{~kg} \mathrm{~m}^{-2}\right)^{-1}$, which is nearly double the sensitivity calculated from the MERRA output.

We note that the stronger observed WVP sensitivity at Tamanrasset (Fig. 6) is least partially due to the fact that the forcing sensitivity is calculated during the nighttime hours, when there is no compensating SW cooling by the water vapor. The higher sensitivity is also likely the result of the drier WVP mean state at the elevated Tamanrasset station. However, we cannot rule out the possibility that this discrepancy may be partially due to a bias in the MERRA surface radiative flux sensitivity to water vapor. Nevertheless, if we assume that the diurnally averaged forcing sensitivity from 

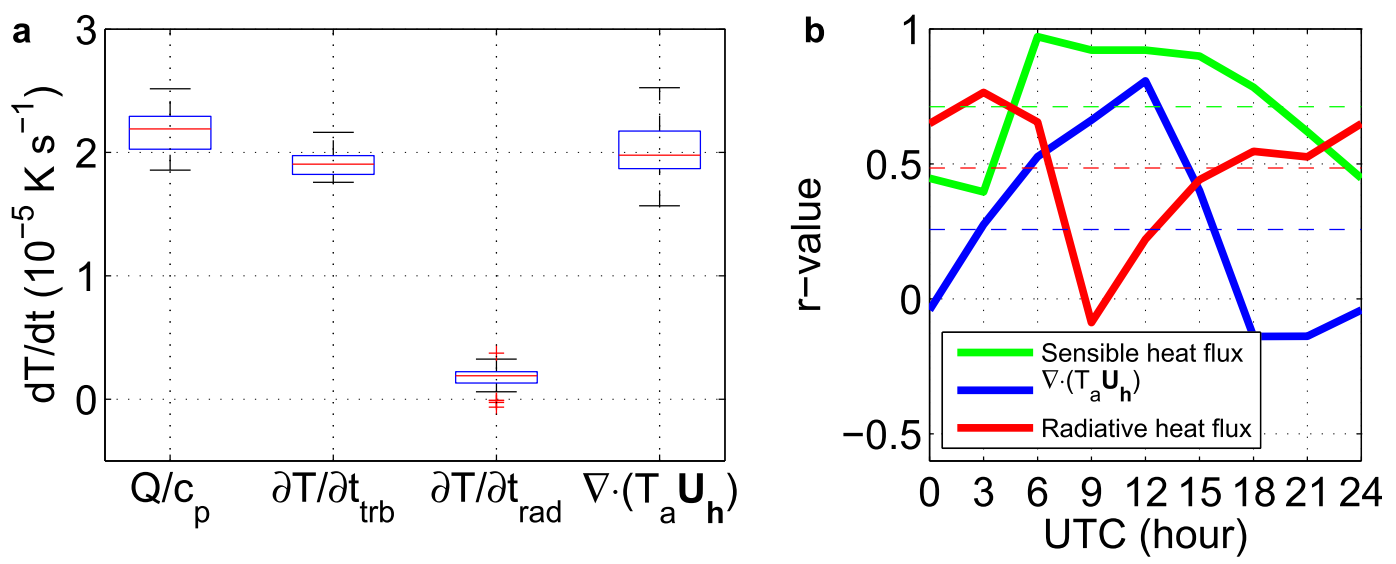

FIG. 7. Analysis of SHL temperature tendencies. (a) Boxplots of the summertime (June-August), from left to right: total diabatic heating, surface sensible heat flux, radiative heat flux, and heat flux divergence. All values are averaged from the surface to $500 \mathrm{hPa}$. (b) The correlation coefficients of the total diabatic heating with the horizontal heat flux divergence (blue), the surface sensible heat flux (green), and the radiative heat flux (red), as a function of time (UTC). All temperature tendencies are for the summertime and are averaged over the SHL and up to $500 \mathrm{hPa}$. Correlation coefficients are for the period 1979-2012, and dashed lines indicate the diurnally averaged mean correlation coefficients.

observations at Tamanrasset is $3.0 \mathrm{~W} \mathrm{~m}^{-2}\left(\mathrm{~kg} \mathrm{~m}^{-2}\right)^{-1}$, which is based on the fact that from the Streamer calculations the diurnally averaged forcing sensitivity is about $85 \%$ smaller than the sensitivity at 0000 UTC, calculations from observations, reanalysis, and Streamer give a SHL water vapor forcing sensitivity range of 1.0 $3.0 \mathrm{~W} \mathrm{~m}^{-2}\left(\mathrm{~kg} \mathrm{~m}^{-2}\right)^{-1}$.

Within the SHL, diabatic heating of the atmosphere is to a first-order approximation controlled by the surface turbulent heat fluxes, which is balanced by horizontal heat flux divergence (e.g., Lavaysse et al. 2009). Boxplots of the reanalysis long-term mean SHL diabatic heating and surface sensible and radiative heat fluxes, all averaged for the summer months and from the surface up to $500 \mathrm{hPa}$, support this finding (Fig. 7a). The median total diabatic heating (which includes sensible, latent, and radiative heating) of the SHL is $2.2 \times 10^{-5} \mathrm{~K} \mathrm{~s}^{-1}$, of which the contribution from the sensible heat flux is $1.9 \times$ $10^{-5} \mathrm{~K} \mathrm{~s}^{-1}$. The contribution from the radiative heat flux to the diabatic heating is an order of magnitude smaller at $1.9 \times 10^{-6} \mathrm{~K} \mathrm{~s}^{-1}$. The median heat flux divergence (where a positive value indicates cooling) is $2.0 \times 10^{-5} \mathrm{~K} \mathrm{~s}^{-1}$ and, to first order, balances the sensible heat flux.

Another way to elucidate the nature of the SHL temperature changes is to calculate the correlation between the summertime surface-500-hPa diabatic heating and the sensible heat flux as a function of time of day (Fig. 7b). The correlation between diabatic heating and the sensible heat flux is a maximum of $0.90-0.97$ ( $p$ value $<$ 0.01 ) from 0600 to $1500 \mathrm{UTC}$ and is a minimum from $0.40(p$ value $=0.02)$ to $0.62(p$ value $<0.01)$ during the nighttime hours. The statistically significant and positive correlations across all times suggest that year-to-year changes in the diabatic heating of the SHL are strongly dependent upon the surface sensible heat fluxes (i.e., dry convection). As such, warming of the atmosphere within the SHL is strongly sensitive to surface temperatures, underscoring the importance of the tight relationship between LW fluxes and water vapor shown in Fig. 6 to the variability and trends in SHL surface and atmospheric temperatures (Figs. 4a,b, 5).

The correlation between heat flux divergence and diabatic heating also peaks, with $r$ values from 0.40 ( $p$ value $=$ 0.02 ) to 0.81 ( $p$ value $<0.01$ ) for $0600-1500$ UTC (Fig. 7b). Our interpretation of this result is that anomalous surface heating triggers dry convection during the daytime hours, which results in a strengthening of the SHL's midlevel anticyclonic circulation and the associated heat flux divergence. This balance between diabatic heating from surface fluxes and dynamic cooling via the SHL's anticyclonic circulation is consistent with earlier work (Lavaysse et al. 2010), the main difference being that we are demonstrating that this balance between surface warming and dynamic cooling exists on interannual time scales.

We also show the correlation between the atmospheric radiative heat flux and diabatic heating of the SHL troposphere (Fig. 7b). Here the correlation peaks during the nighttime and early morning hours $(0000$ 0600 UTC) with $r$ values of $0.65-0.77$ ( $p$ values $<0.01$ ) and is a minimum during the daytime ( $r$ values of -0.09 0.22 , not statistically significant). Our interpretation of these correlations is that during the nighttime hours there is anomalous warming of the atmosphere resulting 
from LW emission from the surface and increased absorptivity in the atmosphere resulting from elevated WVP, but this effect is weakened during the daytime hours as a result of the SW scattering by water vapor (Fig. 6). Consistent with the scatterplot in Fig. 6 and analysis in Fig. 7, there is a statistically significant and positive correlation between summertime WVP and atmospheric radiative heat fluxes from reanalysis $(r=0.88, p$ value $<0.01$; not shown $)$.

\section{d. Moisture budget analysis}

We have used observations and reanalysis to show that SHL surface and atmospheric temperatures are dependent upon the concentration of atmospheric water vapor via greenhouse warming. We next perform a moisture budget analysis with MERRA to elucidate the controls on atmospheric moisture within the SHL. One defining characteristic of a heat low is near-surface moisture flux convergence and midlevel moisture flux divergence (Martin et al. 2014), and here we argue that this horizontal transport of moisture is the dominant mechanism for altering the WVP of the SHL. Here we find that concentration of water vapor in the SHL is, in turn, a function of the temperature of the SHL, and vice versa, a phenomenon we term the Saharan water vaportemperature (SWAT) feedback.

Given that evaporation and precipitation in the hyperarid SHL are nearly zero, the vertically integrated moisture budget of the SHL is to first order only dependent on the horizontal moisture flux divergence and the reanalysis model's assimilation moisture tendency

$$
\frac{\partial \mathrm{WVP}}{\partial t}=-\boldsymbol{\nabla} \cdot(\mathbf{W V P U})+\left(\frac{\partial \mathrm{WVP}}{\partial t}\right)_{\mathrm{ASSIM}},
$$

where $\mathbf{U}$ is the vertically integrated horizontal wind (e.g., Trenberth and Guillemot 1995). The first term on the right-hand side of (1) is the vertically integrated horizontal moisture flux divergence, and the second term is the vertically integrated moisture tendency resulting from data assimilation. An analysis of the longterm mean summertime SHL WVP tendencies is consistent with (1), as WVP tendencies from moist and turbulent processes are an order of magnitude smaller than either the horizontal flux divergence term or the assimilation term (not shown).

The fact that the moisture flux divergence is largely balanced by the assimilation term in (1) makes physical interpretation of the total moisture tendency difficult, principally because there is no way to determine why the model and observations diverge (this could result from inaccuracies in the model or in the assimilated data). However, we think there is still value in examining the output from the reanalysis model. The magnitude of the moisture flux divergence should be related to the temperature and surface pressure minimum of the SHL; as the SHL warms (Figs. 4a,b) and the surface pressure within the SHL region drops (Fig. 5), there is an intensification of the monsoon's shallow meridional circulation (Thorncroft et al. 2011 their Fig. 7b) and an associated anomalous low-level moisture flux convergence into the SHL center with a compensating divergence aloft.

A plot of the MERRA long-term mean moisture flux divergence, averaged over the summer months and the $\mathrm{SHL}$ region, shows low-level (surface- $800 \mathrm{hPa}$ ) moisture flux convergence that is strongest during the nighttime hours and midlevel (800-500 hPa) moisture flux divergence that is strongest during the daytime hours (Fig. 8a). Thus, the reanalysis appears to capture this basic relationship between moisture transport and the circulation of the SHL. To elucidate the moisture flux associated with the SHL's upper- and midlevel circulations, we examine the moisture flux divergence for individual layers within the atmosphere $-\nabla \cdot\left(q_{i} \mathbf{U}_{i}\right)$, where $q_{i}$ and $\mathbf{U}_{i}$ are the specific humidity and horizontal winds of the $i$ th layer of the atmosphere. A plot of the difference in the summertime moisture flux divergence for the 10 warmest years minus the 10 coolest years (via SHL temperatures averaged over the $925-850-\mathrm{hPa}$ layers) shows a statistically significant anomalous moisture flux convergence at the lower levels during the nighttime hours and divergence aloft during the afternoon hours (Fig. 8b), consistent with an intensification of the SHL's climatological circulation (Fig. 7a). Keeping in mind the importance of water vapor greenhouse warming (Fig. 6), our analysis suggests that there exists a positive feedback between SHL water vapor advection and temperature, the SWAT feedback. As the temperature of the SHL increases (Figs. 4a,b) the surface low deepens (Fig. 5) and strengthens the climatological shallow meridional circulation (Fig. 7b). This deepening of the SHL increases low-level nighttime moisture flux convergence (Fig. 8b), which warms the surface via the greenhouse effect (Fig. 6) and subsequently the column via enhanced sensible heat fluxes (Fig. 7b).

Although the SWAT feedback does offer a physically consistent mechanism for the structure of the upward trend in SHL temperatures (Figs. 4a,b), we must also consider the analysis (data assimilation) term in (1). It is not entirely surprising that the assimilation term is of the same order of magnitude as the flux divergence term, since the absolute summertime moisture content in the SHL is very small; SHL surface synoptic stations regularly report single-digit relative humidity values during July and August. It is possible that the moisture data 

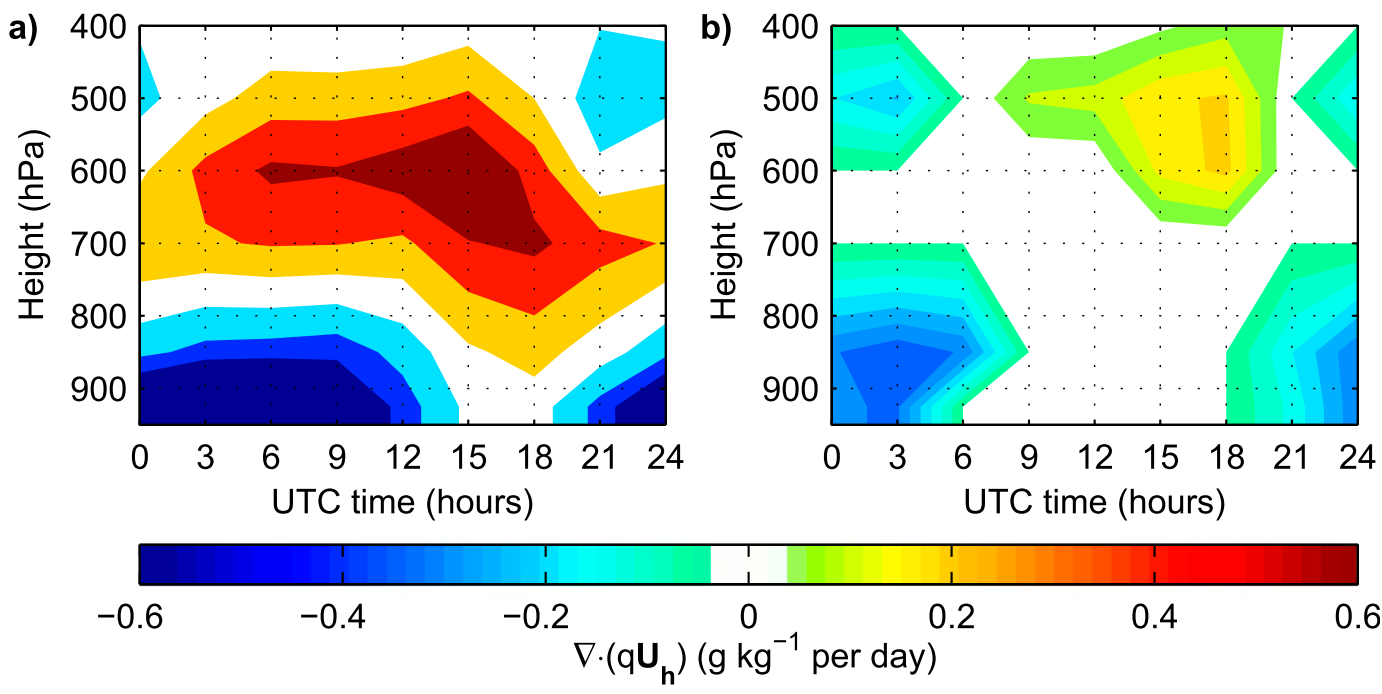

FIG. 8. Climatological and anomalous moisture flux divergence in the SHL. (a) The long-term mean horizontal moisture flux divergence from MERRA, averaged over the SHL, and as a function of time (UTC; abscissa) and height in pressure ( $\mathrm{hPa}$; ordinate). (b) The anomalous moisture flux divergence from the composite difference of the 10 warmest minus the 10 coolest SHL years (calculated as in Fig. 5). Only statistically significant differences ( $p$ value $\leq$ $0.05)$ are shown.

being assimilated into the model is not accurate, which is not implausible given the lack of in situ measurements over the entire SHL. It is also possible that the MERRA anomalous low-level SHL moisture convergence is too strong or that the anomalous midlevel moisture divergence is too weak. Additionally, it is plausible that relatively infrequent monsoon intrusions and precipitation events have a large role in the SHL moisture budget and are not resolved within the physical model. Examination of the model output did not produce a convincing argument for any of these options, given the available data against which the reanalysis could be easily compared. However, we do note that the total WVP tendency [left-hand side of (1)] is larger when the SHL is anomalously warm. The median diurnally averaged WVP tendency for the 10 coldest summers is $0.02 \mathrm{~kg} \mathrm{~m}^{-2}$, and the median WVP tendency for the 10 warmest years is $0.12 \mathrm{~kg} \mathrm{~m}^{-2}$, a factor of 6 larger than that for the cool summers ( $p$ value $=0.01$ ), which is consistent with the SWAT hypothesis (not shown).

We also find evidence for the SWAT feedback in observations; scatterplots of the summertime mean 0600 UTC surface specific humidity and temperature for the three synoptic stations shown in Fig. 1 and over the time periods indicated in Fig. 4a, demonstrate that SHL moisture and temperature are positively correlated (Fig. 9a); the correlations are 0.53 at Tamanrasset $(p$ value $=0.002), 0.42$ at BBM $(p$ value $=0.034)$ and 0.31 at In Salah $(p$ value $=0.095)$. The slopes of the best-fit lines are $0.91 \mathrm{~g} \mathrm{~kg}^{-1} \mathrm{~K}^{-1}$ at Tamanrasset $(p$ value $<$ $0.01), 0.55 \mathrm{~g} \mathrm{~kg}^{-1} \mathrm{~K}^{-1}$ at BBM $(p$ value $<0.05)$ and
$0.34 \mathrm{~g} \mathrm{~kg}^{-1} \mathrm{~K}^{-1}$ at In Salah ( $p$ value $<0.1$ ). We note that a similar scatterplot made from reanalysis, but averaged over the SHL, does not show a statistically significant relationship between specific humidity and temperature. Interestingly, from the synoptic station observations, there was not a statistically significant relationship between specific humidity and temperature at 1500 UTC (not shown). We think this result is consistent with the diurnal cycle in the enhanced low-level heat flux convergence associated with a warming of the SHL (Fig. 7b); as the SHL warms, near-surface specific humidity should build up during the nighttime hours, but dry convection should transport this anomalous moisture to the midlevels in the morning-to-afternoon hours, where there is enhanced moisture flux divergence associated with the midlevel SHL anticyclone.

Lastly, although we only have 10 years of soundings from Tamanrasset that have undergone a qualitycontrol process by ONM (2001-10), it is still useful to examine the relationship between specific humidity and surface temperature with this data. We calculated the correlation coefficient between summertime mean surface temperature at Tamanrasset (same time series used in Fig. 9a) and specific humidity from the 0000 and 1200 UTC soundings, over 2001-10. The results show a positive correlation between moisture and surface temperature within the boundary layer (Fig. 9b), and the correlation coefficients are positive and greater than 0.5 ( $p$ value $<0.1$ ) from the surface up to a height of $650 \mathrm{hPa}$ during the nighttime hours and $600 \mathrm{hPa}$ during the daytime hours. In general, only correlation coefficients 

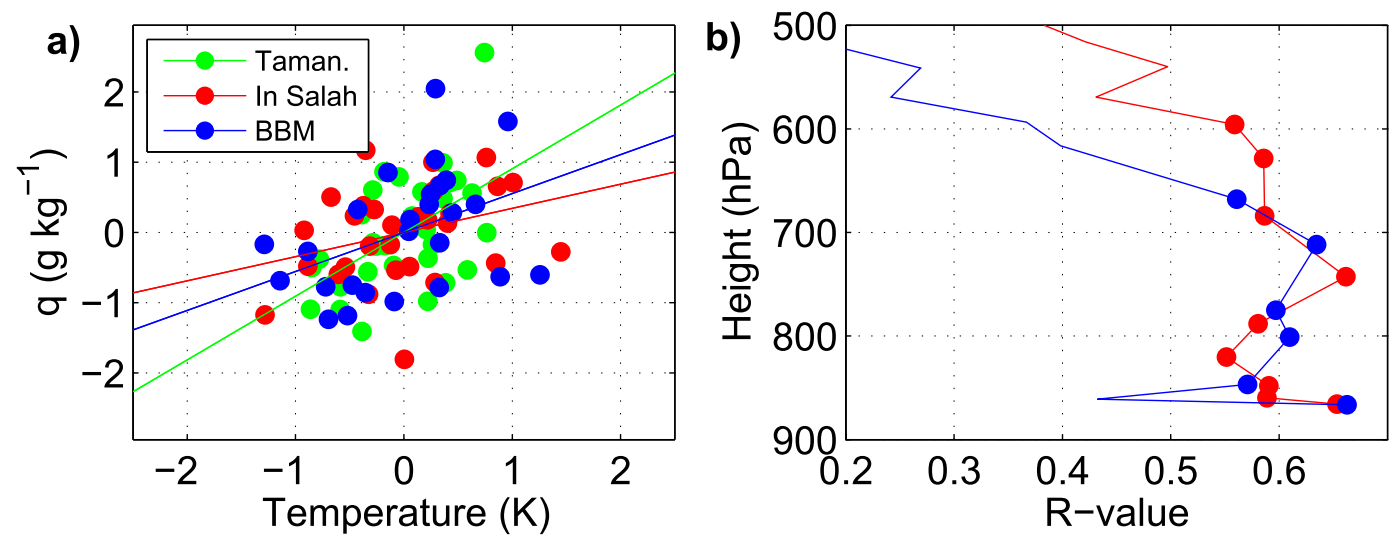

FIG. 9. Observations of the relationship between temperature and moisture. (a) The summertime mean surface temperature (abscissa) and specific humidity (ordinate) from the synoptic stations at Tamanrasset, In Salah, and BBM (Fig. 1). The slopes of the best-fit lines are 0.91 at Tamanrasset ( $p$ value $<0.01), 0.55$ at BBM ( $p$ value $<0.05$ ), and 0.34 at In Salah ( $p$ value $<0.1$ ). (b) Correlation coefficients between seasonal mean specific humidity from the 0000 (blue) and 1200 UTC (red) soundings and surface temperatures from the synoptic stations [as in (a)], over the period 2001-10. Filled circles indicate correlation coefficients that are statistically significant ( $p$ value $<0.1$ ).

greater than 0.6 were statistically significant with $p$ value $<$ 0.05 , which occurs for both soundings near the surface, and between 750 and $700 \mathrm{hPa}$. The positive and statistically significant $(p$ value $<0.1$ ) correlations for the daytime soundings extend higher up in the atmosphere because of the deeper midday boundary layer over the SHL (Figs. 7b, 8). The positive correlation between surface temperature and boundary-layer specific humidity in Fig. 9b is consistent with the SWAT hypothesis and underscores the sensitivity of surface radiative fluxes to WVP (Fig. 6).

\section{Discussion}

We now consider the relevance of the increase in SHL temperature (Figs. 4a,b) with respect to the recovery in Sahelian precipitation over the same period (Fig. 2). Here it is useful to consider an idealized monsoonal circulation that can be described as a large-scale meridional sea breeze. Thus, during the summer months, as the overland part of the circulation warms (the SHL region) and the overwater part of the circulation cools (the Gulf of Guinea region) because of upwelling (de Coëtlogon et al. 2010), there is an anomalous southward surface pressure gradient. This pressure gradient drives the southerly monsoon flow, which transports moisture northward toward the Sahel and is, in effect, the major process responsible for the monsoon onset every June (Sultan and Janicot 2003; Lavaysse et al. 2009). As such, it is reasonable to expect that if the SHL were anomalously warm, or if the Gulf of Guinea were anomalously cool, the monsoonal circulation would become more vigorous, increasing rainfall in the Sahel.
Over the period 1983-2012, there have not been any statistically significant trends in summertime zonally averaged $\left(10^{\circ} \mathrm{W}-10^{\circ} \mathrm{E}\right)$ sea level pressure (SLP) from the Gulf of Guinea up to $23^{\circ} \mathrm{N}$ (Fig. 10), consistent with the increase in Gulf of Guinea SSTs over the same time range (Tokinaga and Xie 2011). However, there has been a statistically significant downward trend in SLP from $23^{\circ}-30^{\circ} \mathrm{N}$, which is consistent with the upward trend in SHL temperatures (Fig. 5). Given an idealized representation of the monsoon circulation, the Sahel rainfall recovery would be associated with an anomalously negative meridional SLP gradient (lower SLP moving northward). The trends in Fig. 10 suggest that

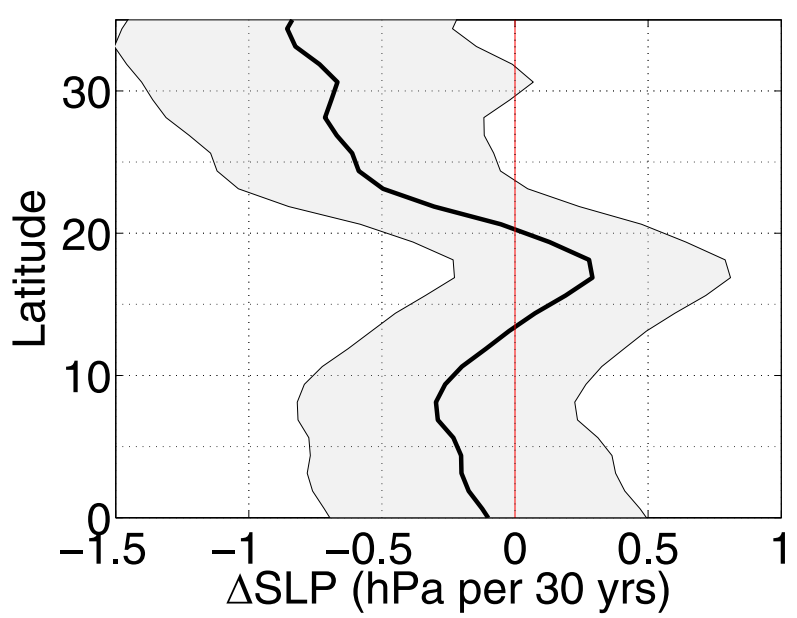

FIG. 10. The 30-yr change in SLP. Shown are the 30-yr trends in MERRA SLP (1983-2012) for the summer season (June-August), averaged from $10^{\circ} \mathrm{W}$ to $10^{\circ} \mathrm{E}$ (black line). The gray shaded region represents the $90 \%$ confidence intervals around the trend values. 
such an anomalously negative SLP gradient can only be due to a deepening of the surface pressure over the SHL region. One could argue that the anomalous warming of the Gulf of Guinea has increased the moisture flux to the Sahel via increased evaporation. However, an analysis of monsoon moisture transport indicates that the increased moisture flux associated with the drought recovery has been farther to the northwest and associated with the West African westerly jet (Pu and Cook 2012).

An analysis of rain gauge data demonstrated that the drought recovery has been limited to the central and eastern Sahel but that drought-like conditions continue to persist in the western Sahel (Lebel and Ali 2009). Such a zonal asymmetry in the precipitation recovery is consistent with an intensification of the SHL and deepening of the low's surface pressure center. Lavaysse et al. (2010) examined synoptic-scale oscillations in the intensity of the SHL, finding that an anomalously deep SHL favors an intensification of the monsoonal southerlies to the east of the low's center and an anomalous northerly flow to the low's west. This large-scale quasicyclonic circulation around the SHL center of action increases the moisture flux convergence and Sahel rainfall to the southeast of the SHL, with the opposite effects to the southwest; as such, it will favor increased precipitation in the central and eastern Sahel but drying to the west (Lavaysse et al. 2010).

We test for an asymmetric response in rainfall to a warming SHL by first estimating the sensitivity of summertime accumulated Sahelian precipitation to SHL temperature, $\partial \operatorname{Pr} / \partial T_{\mathrm{SHL}}\left(\mathrm{mm} \mathrm{K}^{-1}\right)$ via the regression of summertime MERRA SHL temperature (Fig. 4a) onto mean June-August precipitation within the Sahel using three different rainfall records (GPCP, CMAP, and CRU). When calculating $\partial \mathrm{Pr} / \partial T_{\mathrm{SHL}}$ we take the additional step of removing the linear trend in the SHL temperature time series and the linear trends in the precipitation fields as to not bias the sensitivity calculations, although nearly identical results are obtained if we do not take this additional step. We average $\partial \operatorname{Pr} / \partial T_{\mathrm{SHL}}$ from $10^{\circ}$ to $20^{\circ} \mathrm{N}$ and calculate the change in the meridionally averaged precipitation sensitivity from $10^{\circ} \mathrm{W}$ to $20^{\circ} \mathrm{E}$ via linear regression (Fig. 11). A positive zonal gradient in $\partial \mathrm{Pr} / \partial T_{\mathrm{SHL}}$ is interpreted as the influence of an anomalously strong low-level SHL circulation on Sahel rainfall, which favors increased precipitation to the east of the SHL center and reduced precipitation to the center's west.

From the GPCP data, $\partial \mathrm{Pr} / \partial T_{\mathrm{SHL}}$ has a positive zonal gradient of $0.56 \mathrm{~mm} \mathrm{~K}^{-1}$ per degree longitude, which is statistically different from zero $(p$ value $<0.01)$. The CMAP data also show a significant positive zonal

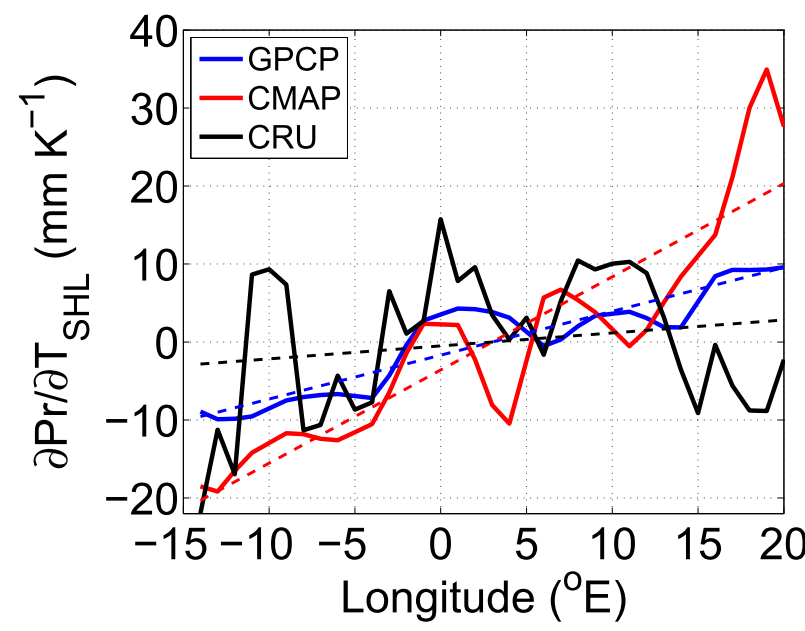

FIG. 11. Zonal changes in the sensitivity of Sahelian rainfall to SHL temperature. Shown is the meridionally averaged $\left(10^{\circ}-20^{\circ} \mathrm{N}\right)$ sensitivity of Sahel precipitation to changes in the temperature of the SHL during the summer months (June-August) for three different precipitation records (solid lines). Also shown are the zonal trends in rainfall sensitivity for each dataset (dashed lines). Linear trends are calculated for 1983-2012.

gradient in $\partial \operatorname{Pr} / \partial T_{\mathrm{SHL}}$, with a value of $1.20 \mathrm{~mm} \mathrm{~K}^{-1}$ per degree longitude $(p$ value $<0.01)$. The CRU data do not exhibit a significant zonal trend in $\partial \mathrm{Pr} / \partial T_{\mathrm{SHL}}$ from $15^{\circ} \mathrm{E}$ to $20^{\circ} \mathrm{W}$, although the CRU trend is statistically significant $(p$ value $=0.05)$ from $15^{\circ} \mathrm{E}$ to $15^{\circ} \mathrm{W}$. Thus, based on the level of agreement between these data, we suggest that the zonal structure in the recovery of the Sahel drought is consistent with forcing by an increase in the intensity of the SHL circulation, also consistent with the rain gauge study (Lebel and Ali 2009).

\section{Conclusions}

In this paper, we have attempted to elucidate processes contributing to the recovery from the Sahelian drought of the 1980s, a period of time we focus on primarily because of the availability of consistent reanalysis products and quality-controlled in situ observations. Although a large body of work suggests that Sahel rainfall changes in step with tropical SSTs, we show that when forced by observed SSTs, most state-of-the-art atmospheric GCMs do not reproduce a statistically significant increase in Sahel rainfall, and the models reproducing a realistic upward trend in rainfall seem to do so for disparate reasons. Based on the multimodel mean trend of Sahelian rainfall, which is one-half the magnitude of the observed trend (Fig. 2), one could argue that one-half of the Sahelian rainfall trends are directly forced by SST changes.

We then examined the role of the SHL in altering Sahelian precipitation. We first established that there 
has been an increase in SHL temperature over the last 30 years and that this increase in temperature has been strongest during the nighttime hours. A heat budget analysis suggested that the trends were forced by anomalous nighttime LW heating of the surface by water vapor. Furthermore, a moisture budget analysis demonstrated that there is an increase in low-level water vapor convergence within the SHL as SHL temperatures go up, a process we termed the Saharan water vapor-temperature (SWAT) feedback.

Interestingly, we do find that two models (HiRAMC360 and GFDL CM3) exhibit a positive correlation between Sahel rainfall and Saharan surface temperatures (Fig. 3), although in these cases, the positive regression coefficients are not limited to the SHL but extend across the Sahara. Perhaps not coincidentally, these two models also have the two largest (and most statistically significant) upward trends in Sahelian rainfall over this period (Fig. 2). However, it is not clear how accurate CMIP5 models are in their representation of SHL thermodynamics and dynamics, and preliminary work has identified persistent biases related to the SHL in these models (R. Dixon and D. Vimont 2014, unpublished manuscript). Therefore, it is difficult to interpret the apparent lack of a relationship between SHL warming and Sahel rainfall in these models.

We demonstrated that the recovery in Sahelian rainfall is consistent with an intensification of the SHL; the rise in SHL surface temperature and accompanying deepening of surface pressure resulted in an anomalous southward meridional pressure gradient, and the zonal asymmetry in the rainfall recovery is consistent with a more vigorous low-level SHL circulation. Nevertheless, the rainfall recovery is clearly not due to the changing nature of the SHL alone. Over this same time period, there has been an increase in moisture advection within the West African westerly jet, which has helped to fuel the increase in monsoon precipitation $(\mathrm{Pu}$ and Cook 2012). In addition, there has been a strengthening of the northward SST gradient in the tropical Atlantic, which may also be associated with an intensification of this westerly jet and an increase in Sahelian rainfall (Hastenrath and Heller 1977; Chiang and Vimont 2004), although the results from Fig. 3 do not support this conclusion. Furthermore, we have not evaluated the relationship between the westerly jet, the tropical Atlantic meridional SST gradient, or Mediterranean SSTs on the thermodynamics and dynamics of the SHL. It is plausible that there exists an anomalous moisture transport into the SHL associated with any of these processes and that the recent SHL warming is partially due to the subsequent SWAT feedback. In other words, warming of regional SSTs or an increase in the hemispheric northward SST gradient may increase the moisture flux into the SHL region, subsequently affecting Sahelian rainfall via greenhouse warming and intensification of the SHL.

Finally, we have ignored the influence of mineral aerosols on the structure of the SHL, in spite of their impact at the synoptic scale as shown by Lavaysse et al. (2011). Accompanying the drought there was an increase in dust advected off of West Africa (Evan and Mukhopadhyay 2010) and presumably an increase in dust over the continent (Evan et al. 2014). However, it is not clear how dust within the SHL may have changed over this period, particularly as the SHL is a persistently dusty region (Fig. 1b), nor is it clear if dust here has a net cooling or warming effect; the SW scattering may be completely balanced by the LW warming, and the LW warming is very sensitive to the microphysical properties of the overland dust (Haywood et al. 2005; Yoshioka et al. 2007).

Acknowledgments. We thank four anonymous reviewers and the editor for their constructive and helpful comments on previous versions of this manuscript. This work benefitted from the support of the French Agence Nationale de la Recherche (ANR) Grant ANR-10LABX-18-01 of the national Programme Investissements d'Avenir. Funding for this work was also provided by Laboratoire d'excellence Institute Pierre Simon Laplace (L-IPSL), a grant from the Research in Paris programme, and National Oceanic and Atmospheric Administration Climate Program Office Grant NA11OAR4310157. CMAP Precipitation data provided by the NOAA/OAR/ESRL PSD, Boulder, Colorado, from their website http://www.esrl.noaa.gov/psd/. Sahel rainfall index data provided by the Joint Institute for the Study of the Atmosphere and Ocean, from their website http://jisao.washington.edu/data/sahel/. CRU data from the Climatic Research Unit, University of East Anglia. Modern Era-Retrospective analysis for Research and Application data was downloaded from the Modeling and Assimilation Data and Information Services Center website http://disc.sci.gsfc.nasa.gov; reanalysis data from the European Centre for MediumRange Weather Forecasts was downloaded from the Meteorological Archival and Retrieval System website http://data-portal.ecmwf.int; and Global Precipitation Climatology Project data was downloaded from the National Climatic Data Center website http://www.ncdc. noaa.gov. Requests for data from the Algerian Office National de la Météorologie should be directed to Mohamed Mokhtari (m.mokhtari@meteo.dz). The Streamer radiative transfer model is available online from http:// stratus.ssec.wisc.edu/streamer/streamer.html. 


\section{REFERENCES}

Biasutti, M., 2013: Forced Sahel rainfall trends in the CMIP5 archive. J. Geophys. Res. Atmos., 118, 1613-1623, doi:10.1002/ jgrd.50206.

_ A. H. Sobel, and S. J. Camargo, 2009: The role of the Sahara low in summertime Sahel rainfall variability and change in the CMIP3 models. J. Climate, 22, 5755-5771, doi:10.1175/ 2009JCLI2969.1.

Cassou, C., C. Deser, L. Terray, J. W. Hurrell, and M. Drévillon, 2004: Summer sea surface temperature conditions in the North Atlantic and their impact upon the atmospheric circulation in early winter. J. Climate, 17, 3349-3363, doi:10.1175/ 1520-0442(2004)017<3349:SSSTCI >2.0.CO;2.

Chauvin, F., R. Roehrig, and J.-P. Lafore, 2010: Intraseasonal variability of the Saharan heat low and its link with midlatitudes. J. Climate, 23, 2544-2561, doi:10.1175/2010JCLI3093.1.

Chiang, J. C. H., and D. J. Vimont, 2004: Analogous Pacific and Atlantic meridional modes of tropical atmosphere-ocean variability. J. Climate, 17, 4143-4158, doi:10.1175/JCLI4953.1.

Collins, J. M., 2011: Temperature variability over Africa. J. Climate, 24, 3649-3666, doi:10.1175/2011JCLI3753.1.

de Coëtlogon, G., S. Janicot, and A. Lazar, 2010: Intraseasonal variability of the ocean-atmosphere coupling in the Gulf of Guinea during boreal spring and summer. Quart. J. Roy. Meteor. Soc., 136, 426-441, doi:10.1002/qj.554.

Dee, D. P., and Coauthors, 2011: The ERA-Interim reanalysis: Configuration and performance of the data assimilation system. Quart. J. Roy. Meteor. Soc., 137, 553-597, doi:10.1002/qj.828.

Diatta, S., and A. H. Fink, 2014: Statistical relationship between remote climate indices and West African monsoon variability. Int. J. Climatol., 34, 3348-3367, doi:10.1002/joc.3912.

Ellingson, R. G., J. Ellis, and S. Fels, 1991: The intercomparison of radiation codes used in climate models: Long wave results. J. Geophys. Res., 96, 8929-8953, doi:10.1029/90JD01450.

Evan, A. T., and S. Mukhopadhyay, 2010: African dust over the northern tropical Atlantic: 1955-2008. J. Appl. Meteor. Climatol., 49, 2213-2229, doi:10.1175/2010JAMC2485.1.

— C. Flamant, S. Fiedler, and O. Doherty, 2014: An analysis of aeolian dust in climate models. Geophys. Res. Lett., 41, 59966001, doi:10.1002/2014GL060545.

Folland, C. K., T. N. Palmer, and D. E. Parker, 1986: Sahel rainfall and worldwide sea temperatures, 1901-85. Nature, 320, 602607, doi:10.1038/320602a0

Giannini, A., R. Saravanan, and P. Chang, 2003: Oceanic forcing of Sahel rainfall on interannual to interdecadal time scales. Science, 302, 1027-1030, doi:10.1126/science.1089357.

— S. Salack, T. Lodoun, A. Ali, A. T. Gaye, and O. Ndiaye, 2013: A unifying view of climate change in the Sahel linking intra-seasonal, interannual and longer time scales. Environ. Res. Lett., 8, 024010, doi:10.1088/1748-9326/8/2/024010.

Harris, I., P. D. Jones, T. J. Osborn, and D. H. Lister, 2014: Updated high-resolution grids of monthly climatic observationsThe CRU TS3.10 Dataset. Int. J. Climatol., 34, 623-642, doi:10.1002/joc.3711.

Hastenrath, S., and L. Heller, 1977: Dynamics of climatic hazards in Northeast Brazil. Quart. J. Roy. Meteor. Soc., 103, 77-92, doi:10.1002/qj.49710343505.

Haywood, J. M., R. P. Allan, I. Culverwell, T. Slingo, S. Milton, J. Edwards, and N. Clerbaux, 2005: Can desert dust explain the outgoing longwave radiation anomaly over the Sahara during July 2003? J. Geophys. Res., 110, D05105, doi:10.1029/ 2004JD005232.
Held, I. M., T. L. Delworth, J. Lu, K. L. Findell, and T. R. Knutson, 2005: Simulation of Sahel drought in the 20th and 21st centuries. Proc. Natl. Acad. Sci. USA, 102, 17 891-17 896, doi:10.1073/ pnas.0509057102.

Huffman, G. J., D. T. Bolvin, and R. F. Adler, 2012: GPCP version 2.2 SG combined precipitation data set. World Data Center for Meteorology, National Climatic Data Center, Asheville, $\mathrm{NC}$, digital media.

Janicot, S., A. Harzallah, B. Fontaine, and V. Moron, 1998: West African monsoon dynamics and eastern equatorial Atlantic and Pacific SST anomalies (1970-88). J. Climate, 11, 18741882, doi:10.1175/1520-0442-11.8.1874.

_ S. Trzaska, and I. Poccard, 2001: Summer Sahel-ENSO teleconnection and decadal time scale SST variations. Climate Dyn., 18, 303-320, doi:10.1007/s003820100172.

Janowiak, J. E., 1988: An investigation of interannual rainfall variability in Africa. J. Climate, 1, 240-255, doi:10.1175/ 1520-0442(1988)001<0240:AIOIRV>2.0.CO;2.

Kanamitsu, M., W. Ebisuzaki, J. Woollen, S.-K. Yang, J. J. Hnilo, M. Fiorino, and G. L. Potter, 2002: NCEP-DOE AMIP-II Reanalysis (R-2). Bull. Amer. Meteor. Soc., 83, 1631-1643, doi:10.1175/BAMS-83-11-1631.

Key, J. R., and A. J. Schweiger, 1998: Tools for atmospheric radiative transfer: Streamer and FluxNet. Comput. Geosci., 24, 443-451, doi:10.1016/S0098-3004(97)00130-1.

Lavaysse, C., C. Flamant, S. Janicot, D. J. Parker, J.-P. Lafore, B. Sultan, and J. Pelon, 2009: Seasonal evolution of the West African heat low: A climatological perspective. Climate Dyn. 33, 313-330, doi:10.1007/s00382-009-0553-4.

,-- and - , 2010: Regional-scale convection patterns during strong and weak phases of the Saharan heat low. Atmos. Sci. Lett., 11, 255-264, doi:10.1002/asl.284.

_ J.-P. Chaboureau, and C. Flamant, 2011: Dust impact on the West African heat low in summertime. Quart. J. Roy. Meteor. Soc., 137, 1227-1240, doi:10.1002/qj.844.

Lebel, T., and A. Ali, 2009: Recent trends in the Central and Western Sahel rainfall regime (1990-2007). J. Hydrol., 375, 52-64, doi:10.1016/j.jhydrol.2008.11.030.

Martin, E. R., and C. D. Thorncroft, 2014: The impact of the AMO on the West African monsoon annual cycle. Quart. J. Roy. Meteor. Soc., 140, 31-46, doi:10.1002/qj.2107.

,-- , and B. B. Booth, 2014: The multidecadal Atlantic SSTSahel rainfall teleconnection in CMIP5 simulations. J. Climate, 27, 784-805, doi:10.1175/JCLI-D-13-00242.1.

Nicholson, S. E., 1994: Desertification. Encyclopedia of Climate and Weather, S. H. Schneider, Ed., Oxford University Press, 239-242.

Peyrillé, P., and J.-P. Lafore, 2007: An idealized two-dimensional framework to study the West African monsoon. Part II: Largescale advection and the diurnal cycle. J. Atmos. Sci., 64, 2783 2803, doi:10.1175/JAS4052.1.

Pu, B., and K. H. Cook, 2012: Role of the West African westerly jet in Sahel rainfall variations. J. Climate, 25, 2880-2896, doi:10.1175/JCLI-D-11-00394.1.

Rácz, Z., and R. K. Smith, 1999: The dynamics of heat lows. Quart. J. Roy. Meteor. Soc., 125, 225-252, doi:10.1002/qj.49712555313.

Rienecker, M. M., and Coauthors, 2011: MERRA: NASA's Modern-Era Retrospective Analysis for Research and Applications. J. Climate, 24, 3624-3648, doi:10.1175/JCLI-D-11-00015.1.

Roehrig, R., F. Chauvin, and J.-P. Lafore, 2011: 10-25-day intraseasonal variability of convection over the Sahel: A role of the Saharan heat low and midlatitudes. J. Climate, 24, 5863-5878, doi:10.1175/2011JCLI3960.1. 
Sultan, B., and S. Janicot, 2003: The West African monsoon dynamics. Part II: The "preonset" and "onset" of the summer monsoon. J. Climate, 16, 3407-3427, doi:10.1175/1520-0442(2003)016<3407: TWAMDP $>2.0 . \mathrm{CO} ; 2$

Taylor, K. E., R. J. Stouffer, and G. A. Meehl, 2012: An overview of CMIP5 and the experiment design. Bull. Amer. Meteor. Soc., 93, 485-498, doi:10.1175/BAMS-D-11-00094.1.

Thorncroft, C. D., and M. Blackburn, 1999: Maintenance of the African easterly jet. Quart. J. Roy. Meteor. Soc., 125, 763-786, doi:10.1002/qj.49712555502.

- H. Nguyen, C. Zhang, and P. Peyrillé, 2011: Annual cycle of the West African monsoon: Regional circulations and associated water vapour transport. Quart. J. Roy. Meteor. Soc., 137, 129-147, doi:10.1002/qj.728.

Tokinaga, H., and S.-P. Xie, 2011: Weakening of the equatorial Atlantic cold tongue over the past six decades. Nat. Geosci., 4, 222-226, doi:10.1038/ngeo1078.

Trenberth, K. E., and C. J. Guillemot, 1995: Evaluation of the global atmospheric moisture budget as seen from analyses. J. Climate, 8, 2255-2272, doi:10.1175/1520-0442(1995)008<2255: EOTGAM $>2.0 . \mathrm{CO} ; 2$.

Vicente-Serrano, S. M., J. I. López-Moreno, L. Gimeno, R. Nieto, E. Morán-Tejeda, J. Lorenzo-Lacruz, S. Beguería, and
C. Azorin-Molina, 2011: A multiscalar global evaluation of the impact of ENSO on droughts. J. Geophys. Res., 116, D20109, doi:10.1029/2011JD016039.

Washington, R., and Coauthors, 2012: Fennec-The Saharan Climate System. CLIVAR Exchanges, No. 60, International CLIVAR Project Office, Southampton, United Kingdom, 31-32.

Xie, P., and P. A. Arkin, 1997: Global precipitation: A 17-year monthly analysis based on gauge observations, satellite estimates, and numerical model outputs. Bull. Amer. Meteor. Soc., 78, 2539-2558, doi:10.1175/1520-0477(1997)078<2539: GPAYMA $>2.0 . \mathrm{CO} ; 2$.

Xue, Y., and Coauthors, 2010: Intercomparison and analyses of the climatology of the West African Monsoon in the West African Monsoon Modeling and Evaluation project (WAMME) first model intercomparison experiment. Climate Dyn., 35, 3-27, doi:10.1007/s00382-010-0778-2.

Yoshioka, M., N. M. Mahowald, A. J. Conley, W. D. Collins, D. W. Fillmore, C. S. Zender, and D. B. Coleman, 2007: Impact of desert dust radiative forcing on Sahel precipitation: Relative importance of dust compared to sea surface temperature variations, vegetation changes, and greenhouse gas warming. J. Climate, 20, 1445-1467, doi:10.1175/JCLI4056.1. 